\title{
Dose-dependent response of plasma ghrelin and growth hormone concentrations to bovine ghrelin in Holstein heifers
}

\author{
Hnin ThidarMyint, Hiroko Yoshida, Tetsuya Ito \\ and Hideto Kuwayama
}

Department of Animal Science, Obihiro University of Agriculture and Veterinary Medicine, Nishi 2-13, Inada, Obihiro 080-8555, Japan

(Requests for offprints should be addressed to H Kuwayama; Email: fujino@obihiro.ac.jp)

\begin{abstract}
The stimulatory effect of the novel gastric-derived hormone, ghrelin, on growth hormone (GH) secretion has been reported in domestic animals as well as in humans and rats. The octanoyl modification on the Ser3 residue of ghrelin appears to be essential for its endocrine activity. A major portion of circulatory ghrelin lacks acylation but possesses some biological activities other than GH stimulation; therefore, both types of acylated and des-acyl ghrelin are supposed to be important for energy homeostasis. The effects of pharmacological doses of rat and/or human ghrelin on GH secretion have been reported recently in ruminants; however, the physiological effect of exogenous bovine ghrelin on its own plasma level and on GH secretion is still unknown. Moreover, the RIA systems for the measurement of bovine active ghrelin and for bovine total ghrelin including acylated ghrelin, des-acyl ghrelin and all ghrelin peptides with an intact bovine C-terminal have not yet been validated. In this study, we established the RIA system for bovine ghrelin, and the dose-dependent effects of synthesized acylated bovine ghrelin(1-27) on plasma active and total ghrelin, $\mathrm{GH}$, insulin and metabolites were measured in Holstein heifers. Six animals were intravenously injected with synthesized acylated bovine ghrelin $(0,0 \cdot 1,0 \cdot 5,1 \cdot 0,5 \cdot 0$, $10 \cdot 0 \mu \mathrm{g} / \mathrm{kg}$ body weight $(\mathrm{BW}))$ and plasma hormone concentrations were measured from serially collected samples. Bovine ghrelin RIA showed that the basal level
\end{abstract}

of total ghrelin is approximately 16 times higher than that of active ghrelin in bovine plasma. Both forms of ghrelin were increased in a dose-dependent manner in response to bovine ghrelin injections, peak values were reached at 5 min after administration and returned to pre-injected values within $15 \mathrm{~min}$. Plasma $\mathrm{GH}$ was responsive to all doses of bovine ghrelin in a dose-dependent manner, peaked as early as at 5-10 min after injection and returned to the basal value within $60 \mathrm{~min}$. The $\mathrm{GH}$ area under curve $1 \mathrm{~h}$ after injection of the smallest dose of ghrelin used in this experiment $(0 \cdot 1 \mu \mathrm{g} / \mathrm{kg} \mathrm{BW})$ was significantly higher than that of the vehicle $(0 \cdot 1 \% \mathrm{BSA}$ saline)-injected control group $(P<0 \cdot 05)$. The $\mathrm{GH}$ response to the highest dose of ghrelin $(10.0 \mu \mathrm{g} / \mathrm{kg} \mathrm{BW})$ was greater than the response to $5 \cdot 0 \mu \mathrm{g} / \mathrm{kg}$ BW ghrelin $(P<0 \cdot 001)$. Plasma glucose concentrations were not significantly altered by the administration of bovine ghrelin while plasma insulin levels were transiently stimulated by the higher doses of ghrelin $(1 \cdot 0,5 \cdot 0,10 \cdot 0 \mu \mathrm{g} / \mathrm{kg} \mathrm{BW})$. Plasma non-esterified fatty acid levels also increased following ghrelin administration. Our study indicates that a considerable quantity of both acylated and des-acyl ghrelin is circulating in the bloodstream, and also confirms that ghrelin is not only a potent stimulator of GH secretion but also plays a considerable role in energy homeostasis in Holstein heifers. Journal of Endocrinology (2006) 189, 655-664

\section{Introduction}

The gastric-derived endogenous ligand of growth hormone secretagogue receptor (GHS-R), ghrelin, has been reported as a novel peripheral growth hormone $(\mathrm{GH})$ stimulant in humans as well as in rodents and domestic animals (Kojima et al. 1999, Hayashida et al. 2001), and acylation on its Ser3 residue with octanoic acid is essential to activate its cognate receptor, GHS-R1a. A considerable amount of another isoform of ghrelin that lacks acylation (des-acyl ghrelin) is also circulating in the bloodstream
(Hosoda et al. 2000a). Des-acyl ghrelin does not possess endocrine activities but promotes bone marrow adipogenesis in vivo (Thompson et al. 2004) and inhibits glucose output by primary hepatocytes (Gauna et al. 2005). Ghrelin is also known as an orexigenic hormone and its effect on feeding is independent of the GH stimulatory pathway (Nakazato et al. 2001). Two molecular types of circulating ghrelin, i.e. ghrelin and des-Gln ${ }^{14}$-ghrelin, have been purified and characterized from rat stomach and both peptides can bind to GHS-R1a (Hosada et al. 2000b). Monogastric animals have both forms of peptide, while 
ruminants only possess des- $\mathrm{Gln}^{14}$-ghrelin because the first splicing acceptor site within intron 1 has been lost (Dickin et al. 2004). Moreover, although the N-terminal region of ghrelin is homologous among species, 7 or 8 amino acids of the C-terminal region of ruminant ghrelin are different from those of monogastric animals (Dickin et al. 2004).

Recent studies investigating the involvement of ghrelin in ruminant physiology have reported that ghrelin immunoreactive cells are present in the abomasum of cows (Hayashida et al. 2001), and that the preprandial increase and postprandial decrease in plasma ghrelin levels are regulated by cholinergic neurons in sheep (Sugino et al. 2004). Furthermore, in vivo and in vitro studies on the effect of ghrelin on the adenohypophysial axis of ruminants have been performed by utilizing supraphysiological doses of rat or human ghrelin (Hayashida et al. 2001, Hashizume et al. 2003, 2005, Itoh et al. 2005), and it has been reported that ghrelin stimulates $\mathrm{GH}$ secretion in dairy cattle at different physiological stages. A very recent study using $1 \mu \mathrm{g}$ human ghrelin $/ \mathrm{kg}$ body weight (BW) showed that ghrelin also has different regulatory effects on plasma pancreatic hormone levels and on glucose concentration (Itoh et al. 2006). However, to our knowledge, there is no report of the dose-dependent effect of bovine ghrelin, especially of physiological doses, on central and peripheral hormones regulating energy homeostatis in ruminants. In this experiment, we validated the radioimmunoassay (RIA) systems for bovine active ghrelin and for bovine total ghrelin, which recognizes acylated ghrelin, des-acyl ghrelin and all ghrelin peptides with an intact bovine C-terminal ghrelin. We also studied the effect of intravenous injection of synthesized acylated bovine ghrelin(1-27) on plasma ghrelin, GH, insulin and metabolite levels in Holstein heifers.

\section{Materials and Methods}

All animal-related procedures used in this experiment were approved by the Institutional Animal Experimentation Ethics Committees of the Obihiro University of Agriculture and Veterinary Medicine, Japan.

\section{Animals}

Six Holstein heifers born at the Field Science Center (FSC), Obihiro University, were housed under a natural light-darkness cycle. Heifers were 6 months old with an average body weight of $178.4 \pm 6.4 \mathrm{~kg}$ ( \pm S.E.M.) at the beginning of the experiment. They were fed twice daily $(0800 \mathrm{~h}$ and $1600 \mathrm{~h})$ with concentrates for growing calves (crude protein $14 \%$, crude fat $1.5 \%$, crude fiber $8 \%$, and crude ash 7\%; Hokuren, Sapporo, Japan) under the routine management practices of the FSC, Obihiro University. Animals finished eating the concentrate within 20 min. Timothy hay, mineral salt block and water were available ad libitum. Body weight was measured one day prior to each injection. At the end of the experiment, heifers had an average BW of $196 \cdot 2 \pm 7 \cdot 8 \mathrm{~kg}$ and the average daily gain during the experiment was $0.89 \mathrm{~kg}$.

\section{Peptides}

$\mathrm{N}$-acylated bovine ghrelin(1-27) (GSSFLSPEHQKLQRKEAKKPSGRLKPR), [Cys-12]-ghrelin(1-11) with acylation and [Cys-0]-bovine ghrelin(11-27) were synthesized by manual Fmoc (9-fluorenylmethoxycarbonyl) solid phase peptide synthesis procedures. Details of the procedures for ghrelin synthesis and octanoylation on the Ser3 residue will be presented elsewhere. Peptidyl resin was cleaved with trifluoroacetic acid (TFA) followed by purification on a TSK ODS-120A column $(7.8 \mathrm{~mm}$ ID $\times 30 \mathrm{~cm}$ ) by high performance liquid chromatography (HPLC, linear gradient of $0-60 \% \mathrm{CH}_{3} \mathrm{CN}$ ), and fractions containing peptides were lyophilized and stored at -80 ${ }^{\circ} \mathrm{C}$. Lyophilized bovine ghrelin(1-27) was dissolved in de-ionized water and diluted to $1 \mathrm{mg} / \mathrm{ml}$ with sterilized $0 \cdot 1 \%$ BSA-saline for the in vivo study.

\section{Antibodies for ghrelin RIA}

Synthesized [Cys-12]-ghrelin(1-11) and [Cys-0]-bovine ghrelin(11-27) were separately conjugated to maleimideactivated mariculture keyhole limpet hemocyanin (mcKLH) and a polyclonal antibody for each antigen was generated in rabbit and guinea pig respectively. The corresponding antibody-containing serum was harvested and stored at $-80{ }^{\circ} \mathrm{C}$. Antiserum against [Cys-12]ghrelin(1-11) only recognizes acyl-ghrelin while antiserum against [Cys-0]-bovine ghrelin(11-27) recognizes C-terminal bovine ghrelin.

\section{Peptide injection and sampling procedures}

Animals were subjected to a complete blocked Latin Square Design (six animals $\times$ six doses of injection $\times$ six days of sampling with one or two days recovery period) to obtain the minimal residual effects. For both injection of peptide and blood sampling procedures, a jugular vein catheter was inserted into each heifer one day before the start of the experiment, and the patency of the catheter was maintained with heparinized saline. Bovine ghrelin(1-27) was freshly diluted with a sterilized solution of $0 \cdot 1 \%$ BSA-saline to reach the desired concentration for each animal before injection. Animals were loosely chained to the stanchion during sampling and were injected with vehicle $(5 \mathrm{ml} \mathrm{0 \cdot 1 \%} \mathrm{BSA-saline} \mathrm{as} \mathrm{control)} \mathrm{or}$ vehicle containing synthesized bovine ghrelin $(0 \cdot 1,0 \cdot 5$, $1 \cdot 0,5 \cdot 0,10 \cdot 0 \mu \mathrm{g} / \mathrm{kg} \mathrm{BW})$ at $1100 \mathrm{~h}(3 \mathrm{~h}$ after the morning feed) via a jugular catheter followed immediately by flushing out of the catheter with $5 \mathrm{ml}$ heparinized saline. 
A

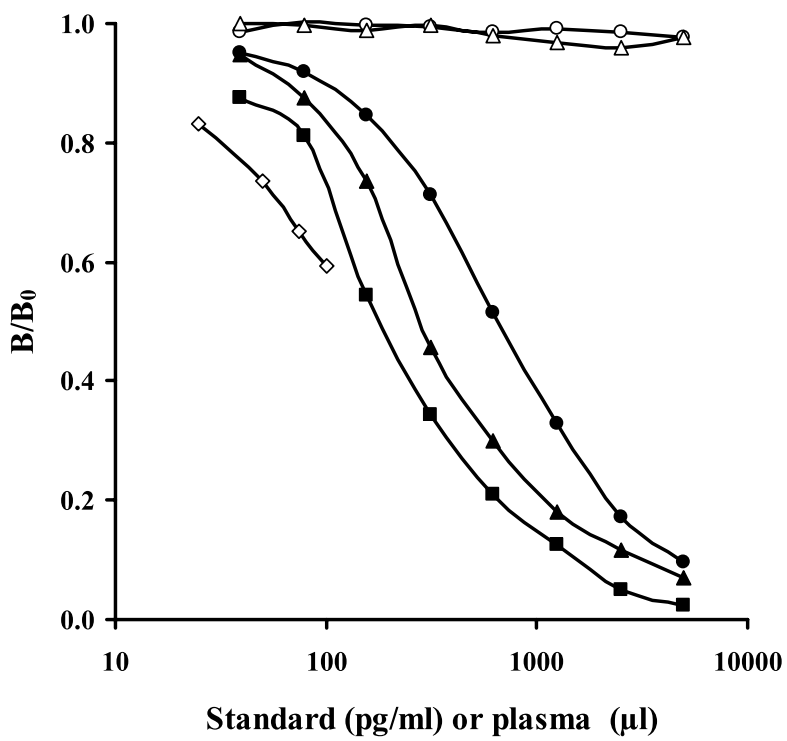

B

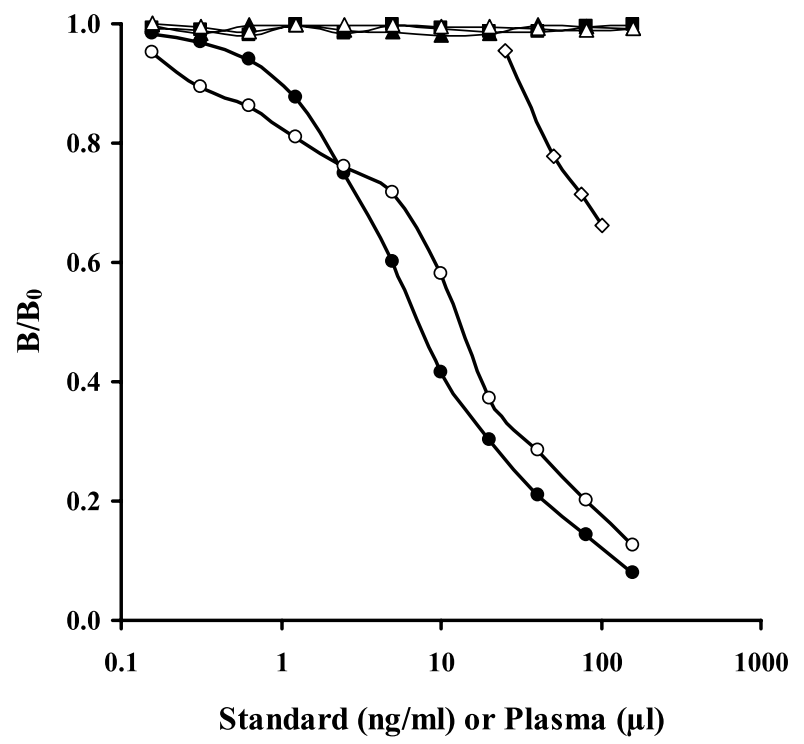

Figure 1 Standard RIA curves for bovine ghrelin. Inhibition of ${ }^{125}$ I-labeled bovine ghrelin binding to rabbit anti-bovine ghrelin(1-11) antiserum (A), and anti-bovine ghrelin(11-27) antiserum (B) by serial dilution of bovine acylated ghrelin (- - ) , bovine des-acyl ghrelin $\left(-\mathrm{O}-\right.$ ), porcine acylated ghrelin $(-\mathbf{\Delta}-)$, porcine des-acyl ghrelin $(-\triangle-)$ and human acylated ghrelin $(-\mathbf{-}-)$. Inhibition of ${ }^{125}$ I-labeled bovine ghrelin binding to both antisera by serial dilution of pooled bovine plasma $(\diamond)$ parallel to the curve was obtained using control full-length bovine ghrelin as standard. Each point is the mean of triplicate determinations. B/BO, bound/bound in zero standard.

Blood samples were collected at $-30,-15,0,5,10,15$, $20,30,45,60,90,120,150,180 \mathrm{~min}$ relative to the time of injection and put into pre-ice-chilled heparinized tubes. Plasma was isolated after centrifugation (3000 r.p.m. $\times 20 \mathrm{~min}$ at $4{ }^{\circ} \mathrm{C}$ ) and stored at $-30{ }^{\circ} \mathrm{C}$ until assay. For plasma ghrelin assay, $600 \mu \mathrm{l}$ plasma were separately acidified with $30 \mu \mathrm{l} \mathrm{M} \mathrm{HCl}$ and stored at $-30{ }^{\circ} \mathrm{C}$.

\section{RIA for bovine ghrelin, GH and insulin}

Acylated bovine ghrelin(1-27) was radioiodinated by the Chloramine-T method (Tai et al. 1975) and purified by HPLC. The tracer was stored at $-80{ }^{\circ} \mathrm{C}$ in $60 \%$ $\mathrm{CH}_{3} \mathrm{CN} / 0 \cdot 1 \%$ TFA and was stable for two months. This tracer ligand was used for both active and total ghrelin assays with acylated bovine ghrelin(1-27) as standard. Standards and plasma samples were incubated with the corresponding antibodies diluted in assay buffer $(0.05 \mathrm{M}$ sodium phosphate containing $0 \cdot 25 \% \mathrm{BSA}, \mathrm{pH} 6 \cdot 85)$. The rabbit anti-bovine ghrelin(1-11) antiserum for active ghrelin RIA and the guinea pig anti-bovine ghrelin(1127) antiserum for total ghrelin RIA were used at final dilutions of 1:240000 and 1:15000 respectively. After $24 \mathrm{~h}$ incubation, ${ }^{125}$ I-bovine ghrelin (8000 c.p.m./100 $\mu \mathrm{l}$ assay buffer containing $1 \%$ carrier serum) was added to all tubes. Bound and free ligands were separated by the second antibody method after a further 24-h incubation, and radioactivity in the pellet was counted with a gamma counter (ARC-1000, Aloka, Japan). Triplicate standards and duplicate samples were run within a single assay at $4{ }^{\circ} \mathrm{C}$, except samples where the concentrations exceeded the range of the total ghrelin assay. These samples were adjusted after re-assay with diluted plasma. Displacement curves of diluted bovine plasma with ${ }^{125}$ I-bovine ghrelin were parallel to the standard curve for both active and total ghrelin (Fig. 1A, B). The average recovery rates of three known amounts of bovine ghrelin added to the bovine plasma pool were 105\% and 106\% for active and total ghrelin respectively. Sensitivities of the present assay were $14.2 \mathrm{pg} / \mathrm{ml}$ and $0 \cdot 14 \mathrm{ng} / \mathrm{ml}, \mathrm{IC}_{50}$ s were $264 \cdot 1 \mathrm{pg} / \mathrm{ml}$ and $8.5 \mathrm{ng} / \mathrm{ml}$, and intra-assay coefficients of variation were $6 \cdot 3 \%$ and $7 \cdot 3 \%$ for active and total ghrelin RIA respectively.

Plasma GH concentration was measured by double antibody RIA procedures (Lee et al. 2000) using bovine GH (USDA-bGH, AFP-9884C) and anti-ovine GH (USDA-anti-oGH AFP-0802201). Sensitivity and the intra-assay coefficient of variation were $0 \cdot 25 \mathrm{ng} / \mathrm{ml}$ and $7 \cdot 3 \%$ respectively. Plasma insulin concentration was quantified as previously described (Inoue et al. 2005) using bovine insulin (28.5 USP units/mg, code I-5500; Sigma Chemical Company) and guinea-pig anti-bovine insulin antiserum (code I-6136; Sigma Chemical Company). Sensitivity and the intra-assay coefficient of variation were $0.05 \mathrm{ng} / \mathrm{ml}$ and $4.0 \%$ respectively. All samples were run in duplicate at $4{ }^{\circ} \mathrm{C}$ for each assay. 

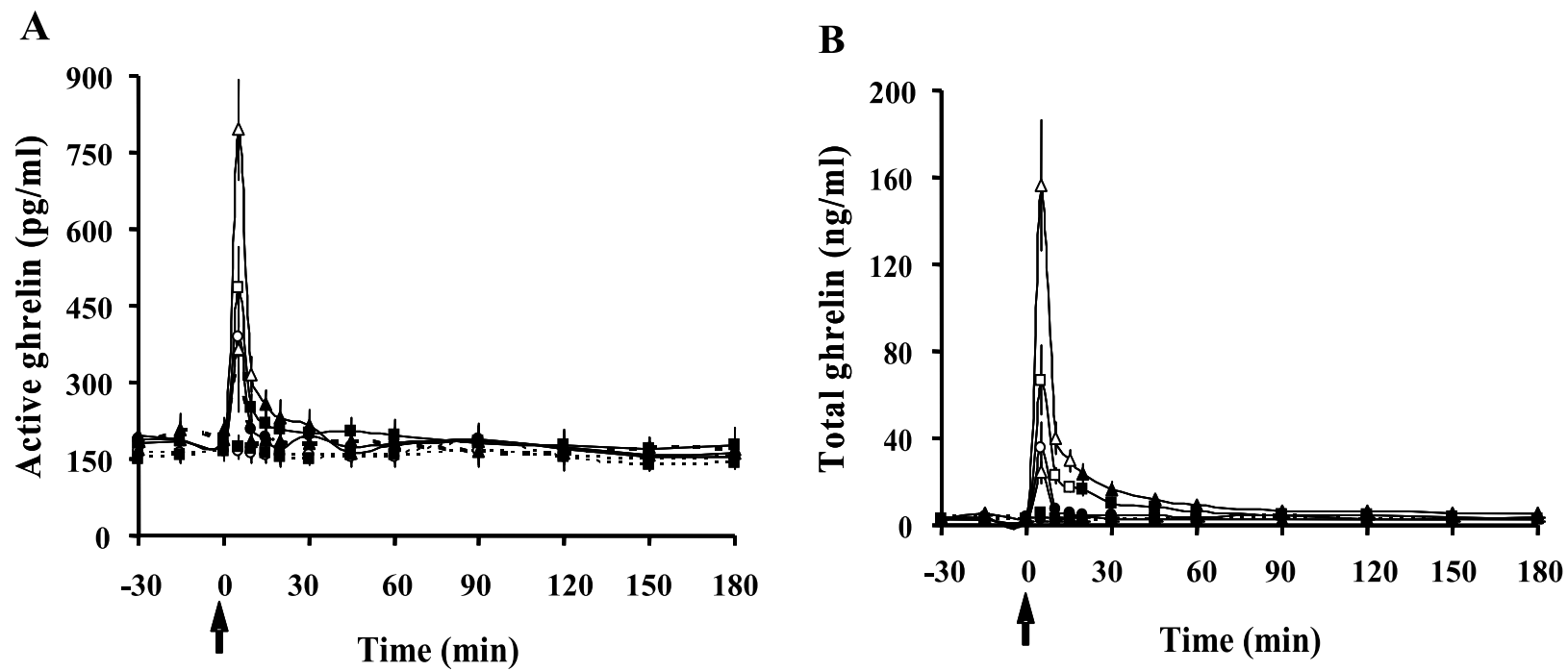

Figure 2 Changes in plasma active (A) and total (B) ghrelin concentration in response to synthetic bovine ghrelin in Holstein heifers.

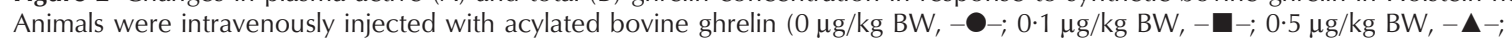

$1.0 \mu \mathrm{g} / \mathrm{kg} \mathrm{BW},-\longrightarrow ; 5.0 \mu \mathrm{g} / \mathrm{kg} \mathrm{BW},-\mathbf{\square}-; 10.0 \mu \mathrm{g} / \mathrm{kg} \mathrm{BW},-\mathbf{\Delta}-$ ) dissolved in $5 \mathrm{ml} 0 \cdot 1 \%$ BSA-saline. Plasma ghrelin concentrations were measured by RIA. The arrow indicates the time of injection. Values are the means \pm S.E.M. of 6 animals. Open symbols indicate a significant difference $(P<0 \cdot 05)$ compared with mean pre-injected concentrations ( -30 to $0 \mathrm{~min}$ ).

\section{Measurements of plasma metabolites}

Plasma glucose and non-esterified fatty acid (NEFA) levels were measured by commercially available kits (code nos 439-90901 and 279-75401 respectively; Wako Chemicals, Osaka, Japan).

\section{Statistical analysis}

All data are expressed as means \pm S.E.M. Statistical differences between averaged pre-injected values (from -30 to $0 \mathrm{~min}$ ) and post-injected concentrations at each time point were analyzed using one-way ANOVA, followed by multiple comparisons of general linear mixed model. Area under the curve (AUC) of each hormone for the 0 to $60 \mathrm{~min}$ response to injection of vehicle or ghrelin was calculated using the trapezoid method and differences were evaluated by Student's paired t-test. All analyses were performed using SPSS for Windows, version $10 \cdot 0 \cdot 0$ (SPSS, Chicago, IL, USA). $P<0.05$ was considered significant.

\section{Results}

The changes in plasma active and total ghrelin responses to synthesized bovine ghrelin are presented in Fig. 2. The RIA for active ghrelin utilizing the rabbit anti-bovine ghrelin(1-11) antiserum showed that there were no differences in pre-injected plasma active ghrelin concentrations in any of the groups $(159 \cdot 0 \pm 19 \cdot 1 \mathrm{pg} / \mathrm{ml})$. Exogenous ghrelin administration increased plasma active ghrelin levels in a dose-dependent manner (Fig. 2A). Significantly higher peak amplitude was seen 5 min after $0.5 \mu \mathrm{g} / \mathrm{kg}$ BW injection compared with pre-injected levels $(363 \cdot 8 \pm 123 \cdot 1$ vs $195 \cdot 1 \pm 33.7 \mathrm{pg} / \mathrm{ml}, P<0 \cdot 01)$ and increased dose-dependently. Thereafter, the elevated active ghrelin levels quickly returned to the pre-injected levels within $10 \mathrm{~min}$. On the other hand, the RIA for bovine total ghrelin utilizing the antibody against bovine ghrelin(11-27) showed that the basal concentration of bovine total ghrelin was $2 \cdot 8 \pm 0.7 \mathrm{ng} / \mathrm{ml}$ and this value is approximately 16 times higher than the basal active ghrelin level. Total ghrelin also increased transiently following synthetic bovine ghrelin injection and returned to the pre-injected values within 5-15 min (Fig. 2B). Similar to the changes in active ghrelin levels, significantly higher peak amplitude was also seen $5 \mathrm{~min}$ after $0.5 \mu \mathrm{g} / \mathrm{kg} \mathrm{BW}$ injection compared with pre-injected levels $(24.1 \pm 5.1 \mathrm{vs} \quad 3.9 \pm 1.5 \mathrm{ng} / \mathrm{ml}, \quad P<0.001)$ and increased dose-dependently.

The response of plasma GH concentrations to bovine ghrelin is presented in Fig. 3. Plasma GH concentrations in the vehicle-injected group did not change throughout the experiment $(2.6 \pm 0.6 \mathrm{ng} / \mathrm{ml})$. Acylated bovine ghrelin(1-27) injection stimulated GH secretion dosedependently. Plasma GH level peaked significantly $5 \mathrm{~min}$ after injection of $0 \cdot 1 \mu \mathrm{g}$ ghrelin $/ \mathrm{kg}$ compared with preinjected values $(6 \cdot 1 \pm 1.9$ vs $2 \cdot 1 \pm 0.5 \mathrm{ng} / \mathrm{ml}, P<0 \cdot 05)$. The peak amplitude and duration of the $\mathrm{GH}$ response were dependent on the dose of ghrelin, i.e. higher doses of bovine ghrelin resulted in increased GH levels over a longer period (Fig. 3). 


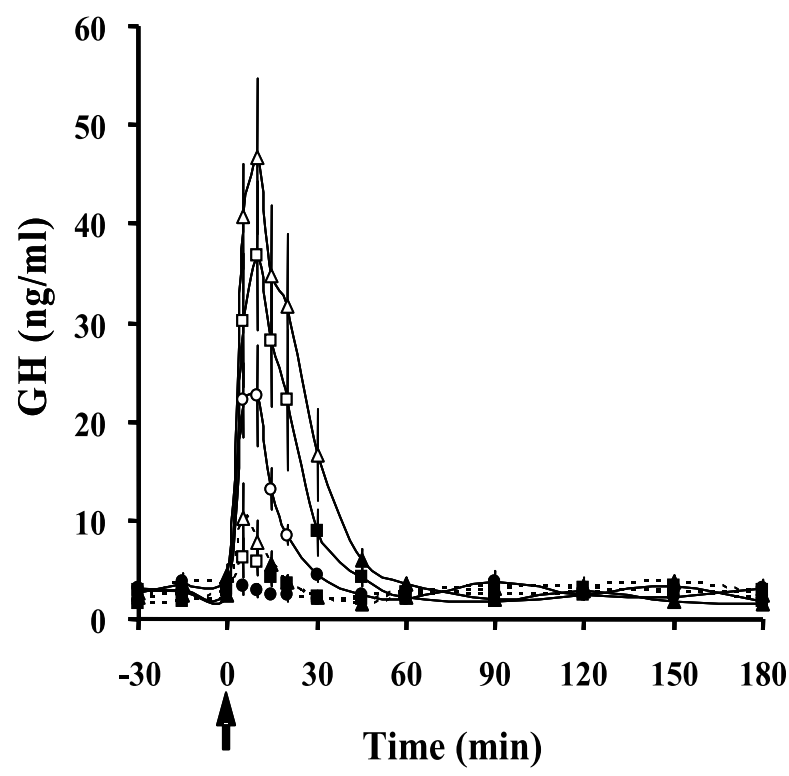

Figure 3 Dose-dependent stimulatory effect of ghrelin on plasma $\mathrm{GH}$ concentration in Holstein heifers. Animals were intravenously injected with acylated bovine ghrelin $(0 \mu \mathrm{g} / \mathrm{kg} \mathrm{BW},-\mathbf{-}-; \cdot 1 \mu \mathrm{g} / \mathrm{kg}$ BW, - - $; 0.5 \mu \mathrm{g} / \mathrm{kg} \mathrm{BW},-\boldsymbol{\Delta}-; 1.0 \mu \mathrm{g} / \mathrm{kg} \mathrm{BW},-\longrightarrow ; 5.0 \mu \mathrm{g} / \mathrm{kg}$ BW, - - $-10 \cdot 0 \mu \mathrm{g} / \mathrm{kg} \mathrm{BW},-\boldsymbol{\Delta}-$ ) dissolved in $5 \mathrm{ml} 0 \cdot 1 \%$ BSA-saline. The arrow indicates the time of injection. Values are the means \pm S.E.M. of 6 animals. Open symbols indicate a significant difference $(P<0 \cdot 05)$ compared with mean pre-injected concentrations ( -30 to $0 \mathrm{~min})$.

The response of plasma insulin to exogenous bovine ghrelin is shown in Fig. 4. Vehicle injection did not modify the plasma insulin level throughout the study $(0 \cdot 7 \pm 0 \cdot 1 \mathrm{ng} / \mathrm{ml})$. The plasma insulin concentration increased, in general, about 10-15 min after ghrelin administration and decreased within 45 min post-injection. Transient but significant peaks were seen only in groups injected with the higher doses of ghrelin $(5 \cdot 0 \mu \mathrm{g} / \mathrm{kg} \mathrm{BW}$ and $10 \cdot 0 \mu \mathrm{g} / \mathrm{kg} \mathrm{BW})$.

Average basal glucose concentration in bovine plasma was $86.5 \pm 2.9 \mathrm{mg} / \mathrm{dl}$ in the vehicle-injected group. Plasma glucose levels increased after ghrelin injection compared with pre-injected values but did not reach significance and the response was independent of the dose given. Moreover, there was a wide variation among animals (data not shown).

Figure 5 shows the effect of synthetic bovine ghrelin on plasma NEFA levels in Holstein heifers. Basal NEFA concentration in the control group $(35 \cdot 7 \pm 3 \cdot 8 \mu \mathrm{Eq} / \mathrm{l})$ was lower than that of the ghrelin-injected groups and significant changes were not seen throughout the experiment. Injection of bovine ghrelin tended to increase plasma NEFA levels but the values did not reach significance compared with pre-injected values when ghrelin was given in low doses $(0 \cdot 1 \mu \mathrm{g} / \mathrm{kg} \mathrm{BW}$ and $0.5 \mu \mathrm{g} / \mathrm{kg} \mathrm{BW})$. On the other hand, plasma NEFA concentration increased

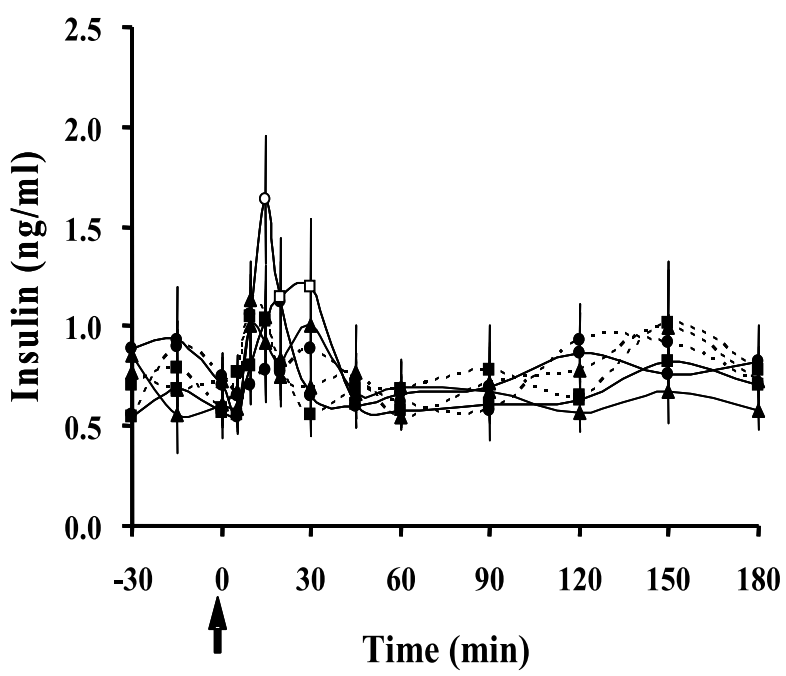

Figure 4 Response of plasma insulin to ghrelin in Holstein heifers. Animals were intravenously injected with acylated bovine ghrelin $\left(0 \mu \mathrm{g} / \mathrm{kg} \mathrm{BW},-\mathbf{O}_{-} ; 0 \cdot 1 \mu \mathrm{g} / \mathrm{kg} \mathrm{BW},-\mathbf{\square}_{-} ; 0.5 \mu \mathrm{g} / \mathrm{kg} \mathrm{BW},-\mathbf{A}_{-}\right.$; $1.0 \mu \mathrm{g} / \mathrm{kg} \mathrm{BW},-\longrightarrow ; 5 \mu \mathrm{gg} / \mathrm{kg} \mathrm{BW},-\mathbf{-}-; 10 \cdot 0 \mu \mathrm{g} / \mathrm{kg} \mathrm{BW}$, - - -) dissolved in $5 \mathrm{ml} 0 \cdot 1 \%$ BSA-saline. The arrow indicates the time of injection. Values are the means \pm S.E.M. of 6 animals. Open symbols indicate a significant difference $(P<0 \cdot 05)$ compared with mean pre-injected concentrations ( -30 to $0 \mathrm{~min}$ ).

as early as $5-10 \mathrm{~min}$ after injection with the higher doses of ghrelin (from $1 \cdot 0 \mu \mathrm{g} / \mathrm{kg} \mathrm{BW}$ to $10 \cdot 0 \mu \mathrm{g} / \mathrm{kg} \mathrm{BW}$ ) and returned to pre-injected values $60 \mathrm{~min}$ later.

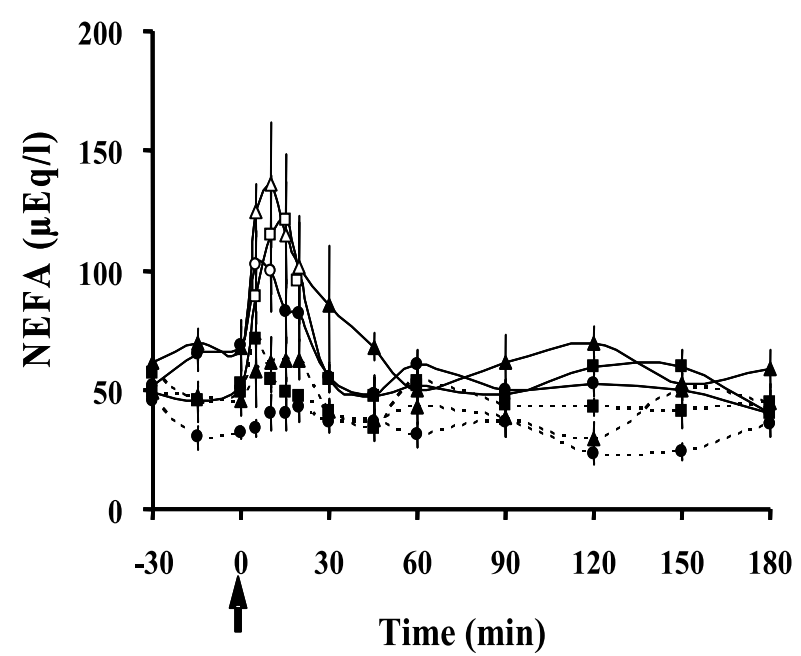

Figure 5 Dose-dependent effect of ghrelin on non-esterified fatty acids (NEFA) in Holstein heifers. Animals were intravenously injected with acylated bovine ghrelin $(0 \mu \mathrm{g} / \mathrm{kg} \mathrm{BW,} \mathrm{--;} 0.1 \mu \mathrm{g} / \mathrm{kg}$ BW, $-\mathbf{\square}-; 0.5 \mu \mathrm{g} / \mathrm{kg} \mathrm{BW},-\mathbf{\Delta}-; 1.0 \mu \mathrm{g} / \mathrm{kg} \mathrm{BW},-\longrightarrow ; 5.0 \mu \mathrm{g} / \mathrm{kg}$ BW, - - $; 10.0 \mu \mathrm{g} / \mathrm{kg} \mathrm{BW},-\boldsymbol{\Delta}-$ ) dissolved in $5 \mathrm{ml} 0 \cdot 1 \%$ BSA-saline. The arrow indicates the time of injection. Values are the means \pm S.E.M. of 6 animals. Open symbols indicate a significant difference $(P<0 \cdot 05)$ compared with mean pre-injected concentrations ( -30 to $0 \mathrm{~min}$ ). 
Table 1 Area under the curve of plasma hormones and metabolites from 0 to 60 min after injection of ghrelin in six Holstein heifers

Dose of synthetic bovine ghrelin $(\mu \mathrm{g} / \mathrm{kg} \mathrm{BW})$

\begin{tabular}{|c|c|c|c|c|c|}
\hline & $0 \cdot 1$ & $0 \cdot 5$ & $1 \cdot 0$ & $5 \cdot 0$ & $10 \cdot 0$ \\
\hline $\mathrm{GH}$ & $128 \pm 23 *$ & $149 \pm 32^{*}$ & $313 \pm 45^{* * *}$ & $562 \pm 124^{\star * *}$ & $797 \pm 143^{* * *}$ \\
\hline Active ghrelin & $100 \pm 8$ & $126 \pm 16^{\star * *}$ & $127 \pm 14^{* * *}$ & $146 \pm 14^{* * *}$ & $163 \pm 16^{\star \star \star}$ \\
\hline Total ghrelin & $110 \pm 27$ & $185 \pm 31^{* * *}$ & $281 \pm 61^{* * *}$ & $612 \pm 96^{* * *}$ & $1127 \pm 210^{* * *}$ \\
\hline Insulin & $98 \pm 16$ & $102 \pm 15$ & $108 \pm 18$ & $112 \pm 15$ & $107 \pm 25$ \\
\hline Glucose & $94 \pm 2$ & $97 \pm 3$ & $98 \pm 3$ & $96 \pm 3$ & $101 \pm 3$ \\
\hline NEFA & $126 \pm 7^{* * *}$ & $131 \pm 10^{* * *}$ & $185 \pm 22^{* * *}$ & $193 \pm 30^{* * *}$ & $238 \pm 38^{* * *}$ \\
\hline
\end{tabular}

Bovine ghrelin was dissolved in $5 \mathrm{ml} 0 \cdot 1 \%$ BSA-saline and intravenously injected at 0 min. AUCs were presented as percentage \pm S.E.M. of vehicle-injected group after subtraction of pre-injected $\mathrm{AUC}(-30 \mathrm{~min}$ to $0 \mathrm{~min})$.

${ }^{*} P<0 \cdot 05,{ }^{* *} P<0 \cdot 001$ vs vehicle-injected control group.

Table 1 summarizes the area under the curves (AUCs) of plasma hormones and metabolites 0-60 min after ghrelin injection. Mean AUCs for six animals were pooled after subtraction of pre-injected AUCs and were expressed as a percentage of the AUC for the vehicle-injected group. Active ghrelin AUC pooled for 0-60 min started to increase significantly when the dose of ghrelin was increased to $0.5 \mu \mathrm{g} / \mathrm{kg} \mathrm{BW}$ compared with that of the vehicle-injected group $(11934 \cdot 2 \pm 1470 \cdot 6$ vs $9472 \cdot 6 \pm$ $1091 \cdot 2 \mathrm{pg} / \mathrm{ml} / \mathrm{min}$ ). Total ghrelin AUC after ghrelin injection at $0 \cdot 1 \mu \mathrm{g} / \mathrm{kg} \mathrm{BW}$ was $110 \%$ of the value of the vehicle-injected group $(172 \cdot 2 \pm 42 \cdot 7$ vs $155 \cdot 9 \pm 35 \cdot 1 \mathrm{ng} /$ $\mathrm{ml} / \mathrm{min})$ and increased dose-dependently $(P<0 \cdot 001)$. Reflecting the changes in $\mathrm{GH}$ concentration, GH AUC for $1 \mathrm{~h}$ post-injection with the smallest dose of bovine ghrelin $(0.1 \mu \mathrm{g} / \mathrm{kg})$ was significantly greater than that of the control group $(P<0 \cdot 01)$. The GH AUC after injection with the highest dose of ghrelin $(10 \cdot 0 \mu \mathrm{g} / \mathrm{kg}$ BW) increased $797 \%$ over that of the vehicle-injected group $(1186.66 \pm 16.95$ vs $148.86 \pm 1.43 \mathrm{ng} / \mathrm{ml} / \mathrm{min}$, $P<0 \cdot 001)$. However, none of the glucose AUCs $1 \mathrm{~h}$ after injection with several doses of ghrelin was significantly different compared with the vehicle-injected group $(5221.3 \pm 112.8 \mathrm{mg} / \mathrm{dl} / \mathrm{min})$. Moreover, insulin AUC did not increase significantly in any of the ghrelin-injected groups compared with the vehicle-injected group $(44.8 \pm 5 \cdot 6 \mathrm{ng} / \mathrm{ml} / \mathrm{min})$. In all ghrelin-injected groups, pooled NEFA AUCs for 0-60 min post-injection were significantly higher than that of the vehicle-injected group $(2208 \cdot 9 \pm 165 \cdot 5 \mu \mathrm{Eq} / \mathrm{l} / \mathrm{min})$.

\section{Discussion}

Feeding time, energy balance, physiological and some pathological states such as obesity influence plasma ghrelin levels in domestic animals as well as in humans (Korbonits et al. 2004). Our previous study demonstrated that plasma ghrelin levels showed nocturnal periodicity and tended to be increased by fasting in pigs (Inoue et al. 2005). In ruminants, circulating active ghrelin levels are lower in 3-month-old calves than in mature cows (Miura et al. 2004). It has also been reported that plasma active ghrelin levels increased preprandially and decreased after feeding in schedule meal-fed sheep (Sugino et al. 2004) but these periprandial changes were not evident in 3-month-old calves (Miura et al. 2004). However, to the best of our knowledge, there is no report to date of circulating total ghrelin levels in ruminants. To remedy this, we validated two RIA systems for bovine ghrelin and in the first instance reported plasma ghrelin levels following synthesized bovine ghrelin administration. In the first RIA system, we used rabbit anti-[Cys-12]-ghrelin(1-11) serum for the measurement of active ghrelin; this antibody does not react with bovine and porcine des-acyl ghrelin (Fig. 1A). Therefore, we consider that the values measured with the first RIA system specifically represent the acylated ghrelin levels. On the other hand, the antibody used for the second RIA system (guinea pig anti-[Cys-0]bovine ghrelin(11-27) serum) reacts with octanoylated bovine ghrelin(1-27) and bovine des-acyl ghrelin, but does not react with porcine acylated ghrelin, porcine des-acyl ghrelin or human acylated ghrelin (Fig. 1B), indicating that this antibody specifically recognizes the C-terminal bovine ghrelin fragment (11-27). Therefore, since the values measured using this RIA system represent acylated ghrelin, des-acyl bovine ghrelin, and all ghrelin fragments with an intact bovine C-terminal region (11-27), we use the term 'total ghrelin' for these values.

The bovine ghrelin RIA showed that both isoforms of ghrelin (acylated and des-acyl ghrelin) are circulating in the bloodstream of Holstein heifers in considerable amounts. This result is in agreement with other reports in human and animal models (Hosoda et al. 2000a, Asakawa et al. 2005). The basal level of total ghrelin is approximately 16 times higher than that of active ghrelin, but it should be noted that this ratio can only be used for the six-month-old heifers and not for animals of other physiological stages such as pre-ruminant animals i.e. calves. In the pre-ruminant stage, ingested liquid feeds by-pass the reticulorumen and enter directly into the abomasum where ghrelin immunoreactive cells exist. After weaning, 
ingested dry feeds are slowly digested by ruminal microbes, and the nature of the nutrients absorbed by the abomasum become different from the pre-ruminant stage. Therefore, weaning may alter the basal plasma levels of the gastric-derived hormone, ghrelin, the secretion of which is influenced by ingested nutrients (Korbonits et al. 2004). This hypothesis is supported by a study in which basal gut hormones such as gastrin, cholecystokinin, pancreatic polypeptide and vasoactive intestinal peptide levels increased, while secretin and somatostatin levels decreased after weaning in Holstein calves (Toullec et al. 1992). Moreover, orally ingested glyceryl trioctanoate rich in milk lipids significantly increases the active ghrelin levels in murine stomach, resulting in the amount of active ghrelin in stomach tissues increasing gradually during the suckling period and decreasing sharply after the initiation of weaning; plasma total ghrelin levels do not change across this transitional period (Nishi et al. 2005). Therefore, it has been suggested that plasma active and total ghrelin concentrations and their ratio in plasma may alter with different physiological stages such as before and after weaning in ruminants.

On the other hand, the role of des-acyl ghrelin in ruminant physiology is still not known. In rat, administration of des-acyl ghrelin decreased food intake and gastric emptying rate through an action on the paraventricular nucleus and the arcuate nucleus in the hypothalamus (Asakawa et al. 2005). Des-acyl ghrelin is supposed to induce negative energy balance, in contrast to acylated ghrelin (Tschöp et al. 2000, Nakazato et al. 2001), and possesses some peripheral effects (Thompson et al. 2004, Gauna et al. 2005). Recently, Iqbal et al. (2006) reported that injection of acylated ghrelin failed to induce voluntary feed intake but significantly stimulated $\mathrm{GH}$ secretion in sheep, while Toshinai et al. (2006) reported that intracerebroventricular injection of des-acyl ghrelin stimulated feeding during the light phase via a distinct pathway from GHS-R in rats fed ad libitum. Therefore, it is suggested that dominant amount of circulating des-acyl ghrelin may also play an important role in mechanisms such as regulation of feeding in ruminants. Further extended studies emphasizing the effects of feeding, physiology and energy states on plasma ghrelin levels, and studies on the role of des-acyl ghrelin in ruminant physiology are necessary.

In this study, both active and total ghrelin levels were only temporarily elevated in plasma after injection of synthetic bovine ghrelin and were degraded/eliminated in the bloodstream within $15 \mathrm{~min}$. This result was consistent with other reports in which the half-life of plasma ghrelin was supposed to be very short (Tschöp et al. 2000, Gauna et al. 2004). Similar results have been reported in weaned pigs; serum ghrelin levels peaked within 15 min of intravenous infusion of human ghrelin $(2 \mu \mathrm{g} / \mathrm{kg} \mathrm{BW})$ and decreased to nearly half-maximal values by $30 \mathrm{~min}$ after infusion (Salfen et al. 2004).
In the dairy industry, it is of economical importance to increase plasma GH secretion because it is associated with faster growth, less fat stores and improved milk production (McMahon et al. 2001). Two hypothalamic hormones, GH-releasing hormone (GHRH) and somatostatin (SRIF) are known to be the main regulators of episodic $\mathrm{GH}$ release from the anterior pituitary gland where GHRH stimulates and SRIF inhibits GH secretion. Other synthetic enkephalin derivatives, GH-releasing peptides (GHRPs, also known as GHSs) also stimulate the secretion of GH (Bowers 1998). The endogenous ligand of GHS-R, ghrelin, has been of interest as a peripheral potent $\mathrm{GH}$ stimulator since it was first purified from rat stomach (Kojima et al. 1999), and several studies have been published on the physiological and pharmacological effects of ghrelin in humans and in domestic animals (Korbonits et al. 2004). It has also been reported that the octanoylation on the Ser3 residue of the N-terminal region is important for ghrelin to activate its receptor, GHS-R1a (Kojima et al. 1999) and short peptides encompassing the first 4-5 residues of ghrelin can activate the GHS-R1a almost as efficiently as the full-length ghrelin (Bednarek et al. 2000). In contrast, truncated peptides of octanoylated ghrelin, such as EP-01037 (Gly-Ser-Ser(Ooctanoyl)-Phe- $\mathrm{NH}_{2}$ ) and EP-00775 (Gly-Ser-Ser(Ooctanoyl)-Phe-Leu-Ser-Pro-Glu- $\mathrm{NH}_{2}$ ) neither stimulate $\mathrm{GH}$ secretion in vivo nor replace radiolabeled ghrelin from binding sites (Torsello et al. 2002). Moreover, bovine ghrelin is a 27 amino acid peptide and 8 amino acids of the C-terminal region (11-27) are heterologous to those of monogastric animals (Dickin et al. 2004). Based on these facts, it is preferable to use a specific peptide to investigate the physiological effect of ghrelin on the mechanism of $\mathrm{GH}$ secretion in ruminants.

In this study, we first reported the dose-dependent stimulatory effect of synthetic acylated bovine ghrelin(127) on GH secretion in Holstein heifers. We used 6 doses of synthetic bovine ghrelin from $0.1 \mu \mathrm{g} / \mathrm{kg}$ BW to $10 \mu \mathrm{g} / \mathrm{kg} \mathrm{BW}$ (approximately $0.033 \mathrm{nmol} / \mathrm{kg} \mathrm{BW}$ to $3.3 \mathrm{nmol} / \mathrm{kg} \mathrm{BW}$ ) in single bolus injections. The minimal dose of bovine ghrelin used in this study induced significantly greater GH AUC 1 hour after injection compared with that of the vehicle-injected control group. The GH peak amplitude also reached significance as early as 5 min after injection. Itoh et al. (2005) also reported that an intravenous bolus injection of human ghrelin $(0 \cdot 3 \mathrm{nmol} / \mathrm{kg} \mathrm{BW}$, approximately equivalent to $1 \mu \mathrm{g} / \mathrm{kg}$ BW) significantly stimulated GH secretion in dairy cattle, and the effect seemed to be more potent in early lactating cows than in calves and in late lactation cows. In contrast, Hashizume et al. (2005) reported that intra-arterial injection of rat ghrelin at $1 \mu \mathrm{g} / \mathrm{kg} \mathrm{BW}$ was not able to stimulate $\mathrm{GH}$ secretion in ovariectomized goats but injection of ghrelin at $3 \mu \mathrm{g} / \mathrm{kg} \mathrm{BW}$ significantly stimulated GH release. Moreover, Iqbal et al. (2006) reported that a bolus injection of ovine ghrelin at a dose of 1, 5, 10 and $20 \mu \mathrm{g}$ 
into the third cerebral ventricle induced a weaker $\mathrm{GH}$ response compared with DAP-octanoyl ${ }^{3}$ human ghrelin injection in ovariectomized ewes. These conflicting results of different responses of $\mathrm{GH}$ to ghrelin injection might be due to differences in experimental conditions, differences in the physiological stage of the experimental animals such as age, different preparations of peptide for injection and the use of human or rat ghrelin which have quite different amino acid residues at the C-terminal region compared with ruminant ghrelin (Dickin et al. 2004). Our results from the dose-dependent study clearly indicated that a physiological dose of bovine ghrelin is sufficient to induce GH secretion in Holstein heifers (Fig. 3 and Table 1) and this is consistent with the results of previous work in humans and rats (Takaya et al. 2000, Hataya et al. 2001, Tolle et al. 2001). Moreover, the highest dose of ghrelin used in this study $(10 \cdot 0 \mu \mathrm{g} / \mathrm{kg} \mathrm{BW})$ still stimulated the secretion of GH significantly more than the $5 \cdot 0 \mu \mathrm{g} / \mathrm{kg} \mathrm{BW}$ indicating that $10 \cdot 0 \mu \mathrm{g} / \mathrm{kg} \mathrm{BW}$ is not the saturation dose for the maximum GH release in Holstein heifers. Altogether, these data suggest that ghrelin is a potent $\mathrm{GH}$ releaser in ruminants.

The increase in plasma insulin concentration in response to synthetic bovine ghrelin injection reached significance at $10 \mathrm{~min}$ when the heifers were injected with $1 \cdot 0 \mu \mathrm{g} / \mathrm{kg} \mathrm{BW}$ while lower doses of ghrelin failed to stimulate insulin secretion. However, none of the insulin AUCs for $1 \mathrm{~h}$ post-injection in the ghrelin-injected groups reached significance compared with the vehicleinjected group. The effect of ghrelin on pancreatic hormones is still unclear. There are some reports suggesting that ghrelin has stimulatory (Date et al. 2002, Lee et al. 2002) or inhibitory (Broglio et al. 2001, Reimer et al. 2003) effects on insulin secretion in humans and rats. Moreover, Salehi et al. (2004) reported that a physiological dose of ghrelin has no effect on glucose-stimulated insulin release from isolated mouse islets while low doses inhibit and high doses stimulate. Furthermore, injection of 1 and $10 \mathrm{nmol}$ ghrelin/kg BW suppresses basal plasma insulin levels in intact mice. A very recent study in ruminants reported that injection of $1 \mu \mathrm{g}$ ghrelin $/ \mathrm{kg} \mathrm{BW}$ has a stimulatory effect on insulin in lactating cows but not in calves (Itoh et al. 2006). Combining these results with ours in which physiological doses of ghrelin failed to elevate insulin levels, it seems that physiological concentrations of ghrelin do not influence insulin secretion. Coincidentally, the injection of physiological or supra-physiological doses of ghrelin failed to induce apparent changes in plasma glucose concentrations in this study. This result is in agreement with other reports in ruminant studies on the effect of KP-102, another potent GH secretagogue (Roh et al. 1996), and ghrelin (Itoh et al. 2006). On the other hand, it was reported that injection of acyl ghrelin induces a rapid rise in insulin and glucose levels but decreases insulin sensitivity in human models (Gauna et al. 2004). These authors also reported in another in vitro study that acylated ghrelin induced while des-acyl ghrelin inhibited glucose output from primary porcine hepatocytes (Gauna et al. 2005). From this dose-dependent study, it is not possible to extrapolate the precise regulatory mechanisms of ghrelin, insulin and glucose in ruminants and more extended studies are needed in these area.

In humans, a 2-h intravenous infusion of acylated human ghrelin $(7.5 \mathrm{pmol} / \mathrm{kg} / \mathrm{min})$ significantly increased not only serum GH concentrations, but also serum NEFA, adrenocorticotropin, epinephrine and prolactin levels when ghrelin was given at a dose of $15 \mathrm{pmol} / \mathrm{kg} / \mathrm{min}$ (Lucidi et al. 2005). In our results in ruminants, a bolus injection of bovine ghrelin stimulated plasma NEFA levels (Fig. 5) but the response was slightly delayed compared with the time-course of ghrelin-induced GH release. This result is similar to a previous report (Roh et al. 1996) in which serial injections of KP-102 resulted in elevation of plasma NEFA levels in Holstein calves. In rodents, chronic ghrelin administration has been shown to increase body fat content and to stimulate the activity of glycerol3-phosphate dehydrogenease and the differentiation of rat parametrial preadipocytes in vitro (Tschöp et al. 2000, Korbonits et al. 2004). These controversial effects of ghrelin on lipid metabolism might be due, at least in part, to differences in species, length (chronic and acute) and dose of peptide administration. One possible explanation for our results is that elevated plasma ghrelin may mimic the temporary negative energy balance in heifers because plasma ghrelin levels were elevated in conditions of energy insufficiency (Korbonits et al. 2004, Anderson et al. 2005). In addition, ghrelin-induced elevation of plasma GH concentration may promote fatty acid degradation (McMahon et al. 2001). As a result, reserved body fat is mobilized to maintain energy balance, leading to the subsequent increase in plasma NEFA concentration (Chilliard et al. 2000). Other factors such as leptin (adipose tissue derived protein), insulin and glucagons may participate in the counter-regulation of fat metabolism with ghrelin.

In conclusion, our dose-dependent study clearly demonstrates that both acylated and des-acyl ghrelin are circulating in the bloodstream in considerable quantities in ruminant species. Moreover, our data show that intravenous injection of ghrelin at physiological doses is sufficient to induce endogenous GH secretion and confirm the potent stimulatory effect of acylated bovine ghrelin on plasma GH secretion in Holstein heifers. Ghrelin also has considerable effects on plasma insulin and NEFA levels indicating that ghrelin plays an important role in ruminant physiology.

\section{Acknowledgements}

We gratefully thank Dr Hidari Hisashi (Field Science Center, Obihiro University of Agriculture and Veterinary 
Medicine) for the experimental animals, Dr A F Parlow (National Hormone and Peptide Program, Torrance, USA) for providing the reagents and procedures for the bovine GH RIA, and the Biosignal Research Center Institute for Molecular and Cellular Regulation, Gunma University for the supply of goat anti-guinea pig serum.

\section{Funding}

This work was partly supported by the Ministry of Education, Science, Sports and Culture of the Japanese government. The authors declare that there is no conflict of interest that would prejudice the impartiality of this scientific work.

\section{References}

Anderson LL, Jeftinija S, Scanes CG, Stromer MH, Lee JS, Jeftinija K \& Glavaski-Joksimovic A 2005 Physiology of ghrelin and related peptides. Domestic Animal Endocrinology 29 111-144.

Asakawa A, Inui A, Fujimiya M, Sakamaki R, Shinfuku N, Ueta Y, Meguid MM \& Kasuga M 2005 Stomach regulates energy balance via acylated ghrelin and desacyl ghrelin. Gut 54 18-24.

Bednarek MA, Feighner SD, Pong SS, McKee KK, Hreniuk DL, Silva MV, Warren VA, Howard AD, Van Der Ploeg LH \& Heck JV 2000 Structure-function studies on the new growth hormone-releasing peptide, ghrelin: minimal sequence of ghrelin necessary for activation of growth hormone secretagogue receptor 1a. Journal of Medicinal Chemistry 43 4370-4376.

Bowers CY 1998 Growth hormone-releasing peptide (GHRP). Cellular and Molecular Life Sciences 54 1316-1329.

Broglio F, Arvat E, Benso A, Gottero C, Muccioli G, Papotti M, van der Lely AJ, Dehenghi R \& Ghigo E 2001 Ghrelin, a natural $\mathrm{GH}$ secretagogue produced by the stomach, induces hyperglycemia and reduces insulin secretion in humans. Journal of Clinical Endocrinology and Metabolism 86 5083-5086.

Chilliard Y, Ferlay A, Faulconnier Y, Bonnet M, Rouel J \& Bocquier F 2000 Adipose tissue metabolism and its role in adaptations to undernutrition in ruminants. Proceedings of the Nutrition Society 59 127-134.

Date Y, Nakazato M, Hashiguchi S, Dezaki K, Mondal MS, Hosoda H, Kojima M, Kangawa K, Arima T, Matsuo H et al. 2002 Ghrelin is present in pancreatic alpha-cells of humans and rats and stimulates insulin secretion. Diabetes 51 124-129.

Dickin JC, Thue TD \& Buchanan FC 2004 An alternative splice site in ghrelin is missing in ruminants. Animal Genetics 35 411-412.

Gauna C, Meyler FM, Janssen JA, Delhanty PJ, Abribat T, van Koetsveld P, Hofland LJ, Broglio F, Ghigo E \& van der Lely AJ 2004 Administration of acylated ghrelin reduces insulin sensitivity, whereas the combination of acylated plus unacylated ghrelin strongly improves insulin sensitivity. Journal of Clinical Endocrinology and Metabolism 89 5035-5042.

Gauna C, Delhanty PJ, Hofland LJ, Janssen JA, Broglio F, Ross RJ, Ghigo E \& van der Lely AJ 2005 Ghrelin stimulates, whereas des-octanoyl ghrelin inhibits, glucose output by primary hepatocytes. Journal of Clinical Endocrinology and Metabolism $901055-1060$.

Hashizume T, Horiuchi M, Tate N, Nonaka S, Kojima M, Hosoda H \& Kangawa K 2003 Effects of ghrelin on growth hormone secretion from cultured adenohypophysial cells in cattle. Endocrine Journal 50 289-295.

Hashizume T, Horiuchi M, Nonaka S, Kasuya E, Kojima M, Hosoda H \& Kangawa K 2005 Effects of ghrelin on growth hormone secretion in vivo in ruminants. Regulatory Peptides 126 61-65.

Hataya Y, Akamizu T, Takaya K, Kanamoto N, Ariyasu H, Saijo M, Moriyama K, Shimatsu A, Kojima M, Kangawa K et al. 2001 A low dose of ghrelin stimulates growth hormone $(\mathrm{GH})$ release synergistically with GH-releasing hormone in humans. Journal of Clinical Endocrinology and Metabolism 86 4552-4555.

Hayashida T, Murakami K, Mogi K, Nishihara M, Nakazato M, Mondal MS, Horii Y, Kojima M, Kangawa K \& Murakami N 2001 Ghrelin in domestic animals: distribution in stomach and its possible role. Domestic Animal Endocrinology 21 17-24.

Hosoda H, Kojima M, Matsuo H \& Kangawa K 2000a Ghrelin and des-acyl ghrelin: two major forms of rat ghrelin peptide in gastrointestinal tissue. Biochemical and Biophysical Research Communication 279 909-913.

Hosoda H, Kojima M, Matsuo H \& Kangawa K 2000b Purification and characterization of rat des-Gln14-Ghrelin, a second endogenous ligand for the growth hormone secretagogue receptor. Journal of Biological Chemistry 275 21995-22000.

Inoue $\mathrm{H}$, Watanuki $\mathrm{M}$, Hnin ThidarMyint, Ito T, Kuwayama $\mathrm{H}$ \& Hidari H 2005 Effects of fasting and refeeding on plasma concentrations of leptin, ghrelin, insulin, growth hormone and metabolites in swine. Animal Science Journal 76 367-374.

Iqbal J, Kurose Y, Canny B \& Clarke IJ 2006 Effects of central infusion of ghrelin on food intake and plasma levels of growth hormone, luteinizing hormone, prolactin, and cortisol secretion in sheep. Endocrinology 147 510-519.

Itoh F, Komatsu T, Yonai M, Sugino T, Kojima M, Kangawa K, Hasegawa Y, Terashima Y \& Hodate K 2005 GH secretory responses to ghrelin and GHRH in growing and lactating dairy cattle. Domestic Animal Endocrinology 28 34-35.

Itoh F, Komatsu T, Kushibiki S \& Hodate K 2006 Effects of ghrelin injection on plasma concentrations of glucose, pancreatic hormones and cortisol in Holstein dairy cattle. Comparative Biochemistry and Physiology. Part A Molecular and Integrative Physiology 143 97-102.

Kojima M, Hosoda H, Date Y, Nakazato M, Matsuo H \& Kangawa K 1999 Ghrelin is a growth-hormone-releasing acylated peptide from stomach. Nature 402 656-660.

Korbonits M, Goldstone AP, Gueorguiev M \& Grossman AB 2004 Ghrelin-a hormone with multiple functions. Frontiers in Neuroendocrinology 25 27-68.

Lee HG, Vega RA, Phung LT, Matsunaga N, Kuwayama H \& Hidari H 2000 The effect of growth hormone-releasing peptide-2 (KP102) administration on plasma insulin-like growth factor (IGF)-I and IGF-binding proteins in Holstein steers on different planes of nutrition. Domestic Animal Endocrinology 18 293-308.

Lee HM, Wang G, Englander EW, Kojima M \& Greeley GH Jr 2002 Ghrelin, a new gastrointestinal endocrine peptide that stimulates insulin secretion: enteric distribution, ontogeny, influence of endocrine and dietary manipulations. Endocrinology 143 185-190.

Lucidi P, Murdolo G, Di Loreto C, Parlanti N, De Cicco A, Fantone C, Taglioni C, Fanelli C, Broglio F, Ghigo E et al. 2005 Metabolic and endocrine effects of physiological increments in plasma ghrelin concentrations. Nutrition, Metabolism and Cardiovascular Diseases 15 410-417.

McMahon CD, Radcliff RP, Lookingland KJ \& Tucker HA 2001 Neuroregulation of growth hormone secretion in domestic animals. Domestic Animal Endocrinology 20 65-87.

Miura H, Tsuchiya N, Sasaki I, Kikuchi M, Kojima M, Kangawa K, Hasegawa Y \& Ohnami Y 2004 Changes in plasma ghrelin and growth hormone concentrations in mature Holstein cows and three-month-old calves. Journal of Animal Science 82 1329-1933.

Nakazato M, Murakami N, Date Y, Kojima M, Matsuo H, Kangawa K \& Matsukura S 2001 A role for ghrelin in the central regulation of feeding. Nature 409 194-198.

Nishi Y, Hiejima H, Mifune H, Sato T, Kangawa K \& Kojima M 2005 Developmental changes in the pattern of ghrelin's acyl 
modification and the levels of acyl-modified ghrelins in murine stomach. Endocrinology 146 2709-2715.

Reimer MK, Pacini G \& Ahren B 2003 Dose-dependent inhibition by ghrelin of insulin secretion in the mouse. Endocrinology 144 916-921.

Roh SG, Matsunaga N, Hidaka S \& Hidari H 1996 Characteristic of growth hormone secretion responsiveness to growth hormone-releasing peptide-2 (GHRP-2 or KP-102) in calves. Endocrine Journal 43 291-298.

Salehi A, Dornonville de la Cour C, Hakanson R \& Lundquist I 2004 Effects of ghrelin on insulin and glucagon secretion: a study of isolated pancreatic islets and intact mice. Regulatory Peptides 118 143-150.

Salfen BE, Carroll JA, Keisler DH \& Strauch TA 2004 Effects of exogenous ghrelin on feed intake, weight gain, behavior, and endocrine responses in weanling pigs. Journal of Animal Science 82 1957-1966.

Sugino T, Hasegawa Y, Kurose Y, Kojima M, Kangawa K \& Terashima Y 2004 Effects of ghrelin on food intake and neuroendocrine function in sheep. Animal Reproduction Science 82-83 183-194.

Tai HH, Korsch B \& Chey WY 1975 Preparation of ${ }^{125}$ I-labeled secretin of high specific radioactivity. Analytical Biochemistry 69 34-42.

Takaya K, Ariyasu H, Kanamoto N, Iwakura H, Yoshimoto A, Harada M, Mori K, Komatsu Y, Usui T, Shimatsu A et al. 2000 Ghrelin strongly stimulates growth hormone release in humans. Journal of Clinical Endocrinology and Metabolism 85 4908-4911.

Thompson NM, Gill DA, Davies R, Loveridge N, Houston PA, Robinson IC \& Wells T 2004 Ghrelin and des-octanoyl ghrelin promote adipogenesis directly in vivo by a mechanism independent of the type 1a growth hormone secretagogue receptor. Endocrinology 145 234-242.

Tolle V, Zizzari P, Tomasetto C, Rio MC, Epelbaum J \& Bluet-Pajot MT 2001 In vivo and in vitro effects of ghrelin/motilinrelated peptide on growth hormone secretion in the rat. Neuroendocrinology 73 54-61.

Torsello A, Ghe' C, Bresciani E, Catapano F, Ghigo E, Deghenghi R, Locatelli V \& Muccioli G 2002 Short ghrelin peptides neither displace ghrelin binding in vitro nor stimulate $\mathrm{GH}$ release in vivo. Endocrinology 143 1968-1971.

Toshinai K, Yamaguchi H, Sun Y, Smith RG, Yamanaka A, Sakurai T, Date Y, Mondal MS, Shimbara T, Kawagoe T et al. 2006 Des-acyl Ghrelin induces food intake by a mechanism independent of the growth hormone secretagogue receptor. Endocrinology 147 2306-2314.

Toullec R, Chayvialle JA, Guilloteau P \& Bernard C 1992 Early-life patterns of plasma gut regulatory peptide levels in calves. Effects of age, weaning and feeding. Comparative Biochemistry and Physiology. Comparative Physiology 102 203-209.

Tschöp M, Smiley DL \& Heiman ML 2000 Ghrelin induces adiposity in rodents. Nature 407 908-913.

Received in final form 3 March 2006

Accepted 17 March 2006

Made available online as an

Accepted Preprint 22 March 2006 